\title{
1. Introducing the issues: meeting the challenges in evaluating homeland security policies
}

\author{
Carol Mansfield and V. Kerry Smith
}

The task of evaluating the benefits and costs of public policies intended to enhance homeland security poses unique problems. After $9 / 11$, the risks faced by the United States (US) population and policies needed to address them were seen in different terms. Prior to 9/11, national defense and security were often used as examples of 'pure public goods' in introductory economics texts. One of the earliest comprehensive texts, by Nobel laureate Paul Samuelson (1976), defined public goods using security as an example. He noted:

Nothing is more vital to a threatened society than its security. But national defense, regarded as a commodity, differs completely from the case of a private commodity like bread. Ten loaves of bread can be divided up in many ways among individuals in a group; but national defense has to be provided more or less automatically for all. (pp. 159-160)

For the most part, discussions of national security as a public good were intended to illustrate the difficulty of measuring the 'amount' of the good and of substantiating the fact that no one is easily excluded from a defense program that protects the US population and the resources that sustain its well-being. For any such program each resident enjoys this umbrella of protection without infringing on others.

Shortly after the US Department of Homeland Security (DHS) was formed in 2002, analysts faced the challenge of developing measures for the amount of protection associated with any homeland security program and what people might be willing to give up to sustain or increase it in a way that conformed to the requirements for policy evaluations. The broad umbrella of security as a pure public good is an $e x$ ante concept, and the reality of meeting threats can involve a complex array of new regulations that inevitably target specific types of activities associated with different types of threats. In many respects the challenge 
that analysts faced was unprecedented. However, there is hope that we can structure a systematic approach to evaluating security policy as an interconnected sequence of individual rules placing limits on private behavior.

Our goal here is to convince you that the issues are new but the task is do-able. To develop a platform for policy evaluation, we must acknowledge that we need to learn by doing the regulatory impact analyses assessing the major rules associated with the implementation of security policy. And in designing the preliminary template for analyses of rules, we need to identify strategies that are especially robust to surprises, as well as to complementarities among programs, which cannot be easily anticipated. For example, complementarities could arise with perceived safety. Suppose, for example, that the policies designed to reduce specific individual risks also reduced the 'feeling of being unsafe', or what we might refer to as the ambiguity of risk, ${ }^{1}$ by assuring the public that some sources of risk were effectively 'off the table'. An individual analysis of each risk source might provide estimates that imply a relatively small positive value for the net benefits for each activity associated with an individual rule. That is, the margin of benefits over costs might be small enough so one could reasonably assert that when the estimation errors are considered, the net benefits could be negative. Nonetheless, analysts might want to point out that the overall impact of rules reducing the security risks people face also had the collective effect of enhancing 'feelings of safety'. Under these circumstances the set of rules would accomplish more as a composite than the sum of the net benefits estimated for each one of them. Of course, such claims are difficult to substantiate. The bottom line, then, is that to structure analysis strategies to overcome challenges, we need practical methods for the near term that recognize that security has many dimensions: risk reduction, less ambiguity or generalized uncertainty in daily activities, and greater assurance that the infrastructure supporting activities of daily living will not be disrupted. Security is embedded in all we do, so we should expect that it will be difficult to enumerate each component. Equally importantly, we cannot be expected to fully anticipate how people and institutions will adapt to these new threats and public actions to reduce them. Therefore, 'analysis sprinkled with caution' may be warranted.

Security policy evaluation poses special challenges for five reasons. Firstly, the 'outputs' of new rules are not easily connected to the risks they seek to address. Secondly, but equally importantly, there are few situations in which people make choices that unambiguously reveal the trade-offs they are willing to make to reduce risks. Thirdly, while securityrelated events can harm people and destroy assets, these effects are only a part of their impact. Fear is a public bad. Inability to quantify the risks 
of some actions (ambiguity in the risks) has negative effects that are distinct from events that lead to reasonably well-understood increases in the risks of bad outcomes. Fourthly, threats arise as a result of other people's decisions, so once any policy of the 'target economy' is recognized by the group that is initiating the threat, we should expect to encounter changes in the behavior of those seeking to do harm. In contrast to environmental policy, where concentration-response functions follow set patterns, risk assessment of terrorist threats must reflect strategic behavior on the part of the agents who are the source of the risk and the focus of policy. Fifthly, evaluations of security policies must be completed in a timely fashion, but with much less data and experience than is available for most of the other common areas of regulatory analysis. Policy delays in the case of securityrelated decisions can have especially significant impacts. For these five reasons, we conclude that the evaluation of homeland security policies, and the benefit-cost analysis of the regulations that stem from such policies, is new terrain.

In the fall of 2010, the National Center for Risk and Economic Analysis of Terrorist Events (CREATE) at the University of Southern California sponsored a workshop to take stock of what we knew for meeting the tasks associated with doing regulatory impact analyses for homeland security policies and to assess how experience in other areas might be adapted to the special requirements for evaluating these policies. Early versions of the chapters in this volume were discussed at that workshop, with academics and analysts from DHS. After the workshop, the papers were revised, new research was completed, and new papers were written. All of that work is reflected in this volume.

The chapters that comprise this volume share a problem context, which we discuss in two parts. We begin with a summary of the rapid development of DHS, and of the scale of the activities included in this relatively new, cabinet-level department. Then we comment on two of the DHS rules included in United States Office of Management and Budget (OMB)'s 2010 Report to Congress on the Benefits and Costs of Federal Regulations and Unfunded Mandate on State, Local and Tribal Entities. Finally, the last section of this chapter provides a short guide to the chapters that follow, explaining why they are here, and how they relate to our overall goal: developing a platform for the economic evaluation of security-related regulations. 


\section{DHS: THE BEGINNING, THE SCOPE, AND THE IMPACT ON ECONOMIC ACTIVITY}

A little over a year after the 2001 attack on the World Trade Center, Congress passed the Homeland Security Act (2002) and DHS was established as a cabinet-level department. The primary mission of the department is to:

prevent terrorist attacks within the United States; reduce the vulnerability of the United States to terrorism; and minimize the damage, and assist in the recovery from terrorist attacks that do occur within the United States. (Public Law 107-296, November 25, 2002; Section 101, 116 Stat. p. 2142)

DHS was given four areas of responsibility:

- chemical, biological and nuclear countermeasures;

- information analysis and infrastructure protection;

- border and transportation security; and

- emergency preparedness and response. (Pub. L. 107-296, November 25, 2002; Section 101, 116 Stat., p. 2)

Each area had a number of sub-areas. The President's 2003 budget anticipated that the department would have over 169000 employees, measured as full-time equivalents (FTEs). A little over a decade later, the President's 2014 budget estimated an increase in FTEs of 35 percent, to nearly 229000. Budgeted expenditures in nominal terms have increased 60 percent from $\$ 37.5$ billion to $\$ 60.0$ billion. Figure 1.1 provides an organization chart for the composition of the department as of 2013. As this diagram suggests, DHS has a number of responsibilities that are not directly related to security but could be viewed as complementary activities.

For both of the years we described, these budget figures do not include the resources associated with the Federal Bureau of Investigation, the Central Intelligence Agency, the National Security Agency, and other agencies that provide support to assist DHS in its mission. They also do not reflect the resources that US residents implicitly expend in the form of time spent waiting in lines to clear airport security or at US borders to enter the country.

Of course, many security activities were underway before $9 / 11$, and some do not have a direct connection to homeland security. The President's 2014 budget allocates about 42 percent ( $\$ 25$ billion) to 'non-homeland security' functions. The Federal Emergency Management Agency (FEMA) and the 


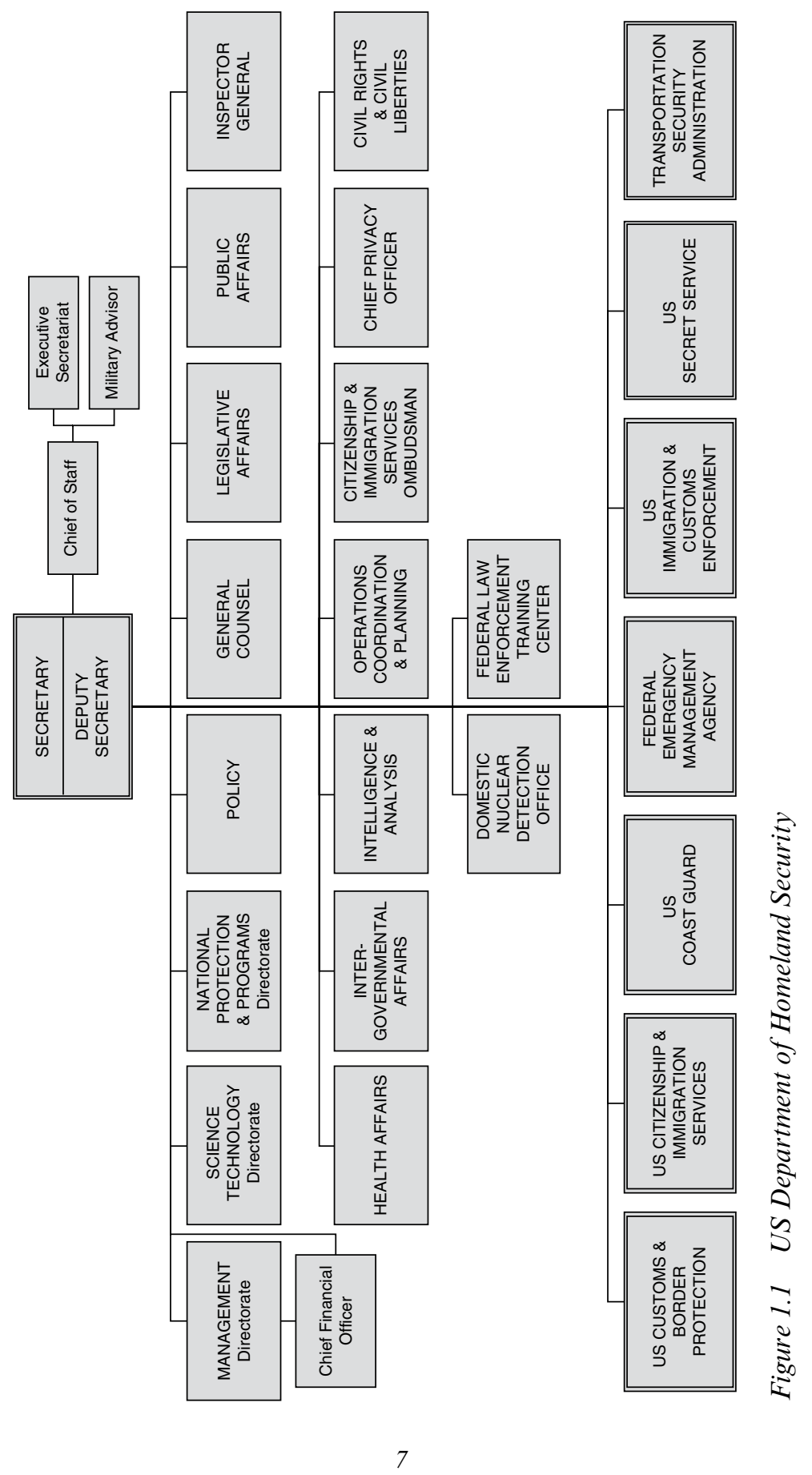


Coast Guard operations that are not associated with homeland security account for half of this $\$ 25$ billion. Nonetheless, $\$ 35$ billion in annual expenditures for homeland security suggests that the agency engages in a large set of activities. Yet those activities are not the full story. Indirect costs are important as well. Immediately after $9 / 11$, analysts examined the indirect effects of security measures. For example, Navarro and Spencer (2001) estimated that the bulk of the costs of increased aviation security would be due to waiting time. They estimated that if 550 million passengers each required 90 minutes of added time to complete their trips, with shadow values of time between $\$ 10$ and $\$ 40$ an hour, then the overall indirect costs of the requirement for passenger screening would be $\$ 8$ billion to $\$ 32$ billion annually. A year later, a separate assessment by Hobijn (2002) suggested lower aggregate costs of about $\$ 12$ billion, using lower estimates of the opportunity costs of time. Regardless of the estimate used, these are large costs.

Examining the costs of homeland security from 2001 to 2005, Hobijn and Sager (2007) concluded that the costs had not led to a slowdown in economic activity. They based this conclusion on the growth rate in average labor productivity and the inventory-to-sales ratio from the business sector. They found that neither index was substantially affected. Since the costs of homeland security programs rose from about 0.5 percent of gross domestic product (GDP) in 2001 to nearly 1 percent in 2005 , it seems reasonable to conclude that the programs did not markedly constrain economic activity during those years. Hobijn and Sager's (2007) conclusion might be used to suggest that the perception of safety is more important to economic activity than these relatively small additions to the costs of daily activities. With the dramatic downturn of the US economy in 2007, it is likely that sustained government spending, as well as the process of maintaining and increasing personnel and capital expenditures for these programs, helped to bolster private demand of other goods and services.

While the aggregate impact of homeland security programs on growth seems small, it is nonetheless important to consider the net benefits we realize from new rules and major modifications to existing programs. With federal programs that require commitments approaching 1 percent of GDP, it is important to consider ways that objectives might be achieved more efficiently. Executive Order 13563 did just that. It required each executive-branch agency to develop plans to periodically review the regulations associated with each agency's responsibilities and identify when the regulations should be 'modified, streamlined, expanded or repealed' (Executive Order 13563, issued 1/18/2011, Federal Register, Vol. 76, No. 14, p. 3822). The goal of the requirement is to ensure that the objec- 
tives of the rules can be achieved and to determine if the associated programs could be implemented in a less burdensome way.

DHS's final plan for reviewing significant regulations under the order is a three-step process involving rule selection, prioritization, and efficiency assessment (Department of Homeland Security, 2011). The document describing these steps outlines the process of meeting each component in very general terms, detailing the sources of input information to the task without explaining specific criteria. Therefore, it is difficult to comment on the issues considered in implementation. For example, in discussing rule selection, the plan identifies public feedback as a primary factor and the experience of public officials as a secondary factor. Under the primary factor the plan suggests that DHS is looking for new information and new economic data to support proposed changes. It does not identify an internal process to proactively evaluate performance metrics as part of its implementation.

Rules for retrospective evaluation are supposed to be prioritized according to measures of the net benefits of changes. More specifically, the regulation review plan states that:

DHS will seek to measure net benefits against a baseline. The baseline is the best assessment of how the world will look in the future with the regulation in place. This will be compared to an estimate of how the world would look if the regulation were modified, streamlined, expanded, or removed. DHS will afford higher priority to those regulations that are likely to generate higher net benefits (greater reductions in net costs). ${ }^{2}$

Unfortunately, when the plan discusses benefit-cost analysis more specifically, it concludes: 'After reviewing the public comments received in response to our March 2011 Federal Register notice, IdeaScale webpage, and DHS Preliminary Plan, and after considering the discussions at the Department-wide Working Group on retrospective review, our preliminary analysis indicates that a significant number of retrospective analyses will not require extensive cost-benefit studies' ${ }^{3}$ Moreover, a key reason for this assessment, according to the plan, is the absence of 'high-quality' data to perform these analyses. This reaction to the comments DHS had received was widely recognized within DHS before the plan was finalized, and was also an important motivating factor for the 2010 CREATE workshop of which this book is an outcome. The DHS (2011) report on the plan for conducting retrospective analyses supports these efforts directly, noting an absence of the substantive information that would be required for retrospective benefit-cost analyses to be informative. This report observes that: 
The Department believes obtaining quality data could be a challenge for the retrospective analyses of its regulations. GAO [the Government Accountability Office] has reached similar conclusions, noting, in the past, that the inability to obtain the information and data needed to conduct retrospective analyses is a major barrier to such reviews. Thus far, there has been a lack of substantive benefit-cost data from the public. For example, in our March 2011 Federal Register notice, we specifically posed questions such as - 'What information, especially new or additional information or data, regarding the costs and benefits of these regulations are available?' - to help facilitate public comments in this area. We did not receive any substantive information or data from the public that would assist us in conducting retrospective benefit-cost analyses. ${ }^{4}$

Of course, the same comment about data needs could be noted for analyses undertaken as part of the regulatory impact analysis (RIA) process itself.

The goals of the Executive Order and the concerns stated in the plan for retrospective analyses are consistent with recent mandates from the Executive Branch. In July 2013 the director of OMB, along with the directors of the Domestic Policy Council, the Office of Science and Technology Policy, and the chairman of the President's Council of Economic Advisers, called for agencies to:

- harness data to improve agency results;

- conduct high-quality, low-cost evaluations and rapid interactive experimentation;

- use innovative, outcome-focused grant designs; and

- strengthen agency capacity to use evidence (Burwell et al., 2013).

Responding to these mandates will be challenging for DHS. The agency does not have a history of experience with benefit-cost analysis and program evaluation generally. The research in this volume describes how the department can begin to address this directive.

\section{SOME EXAMPLES OF DHS BENEFIT-COST ANALYSES}

RIAs prepared by DHS provide the best examples of the problems encountered trying to quantify and value the benefit analysis for homeland security rules. We will examine two examples: the Western Hemisphere Travel Initiative (WHTI) and the proposed Air/Sea Biometric Exit Project (Exit). Both of these analyses were conducted in 2008 (see Industrial Economics Inc., 2008; US DHS, 2008). The WHTI states that, as of June 2009, US citizens and non-immigrant aliens from Canada, Bermuda, and Mexico 
entering the US at land and sea ports of entry from Western Hemisphere countries must present a valid passport, passport card, or other acceptable document in circumstances in which travel was previously permitted without such a document. The proposed Exit system would verify in a reliable and timely manner whether those people who entered the US legally had departed, and it was expected to significantly improve on the information available from the paper-based Form I-94 process. $^{5}$

Using the Exit RIA as an example, the RIA summarizes the benefits and describes whether the benefits were monetized, quantified but not monetized or qualitatively assessed in a tabular form. It also maps the goals of DHS with the potential benefits of the proposed Air/Sea Biometric Exit Benefits rule. We reproduce both these tables in Tables 1.1 and 1.2, respectively. The RIAs for both the WHTI and Exit rules identified 'increased national security' as one benefit, and outlined three sets of information that would be needed to quantify and monetize the improvements: ${ }^{6}$

1. Estimates for the baseline probability that a successful terrorist attack will occur.

2. Estimates of incremental reductions in the baseline probability of a successful terrorist attack that would result from the implementation of the regulation and the consequences of the avoided event (collectively, the risk associated with a potential terrorist attack). Combining (1) and (2) would provide a measure of the risk reduction attributed to the rule.

3. Estimates of the average per individual (or household) willingness to pay (WTP) for the reduction in this type of risk. Using the incremental risk reduction together with estimates for the willingness to pay for a unit reduction in risk, the analyst has an assessment of the ex ante trade-off that an individual (or a household) would make to obtain the policy that is assumed to be responsible for the risk reduction.

The next step in the description in the RIA specifies that this average trade-off should be multiplied by the number of individuals experiencing the risk reduction. ${ }^{7}$

The RIAs identify the important data questions that arise in each of these steps. First, data on terrorist attacks and their consequences during the last decade are limited. Therefore, the task of assessing baseline risk is exceptionally difficult. ${ }^{8}$ Moreover, the mechanism linking the policy to the risk reduction is problematic. The RIA outlines several reasons why DHS felt that historical data might not be appropriate. For example, it was difficult to determine whether documented attacks can be attributed to how entry procedures treat people who lack a passport. The RIA argued that 


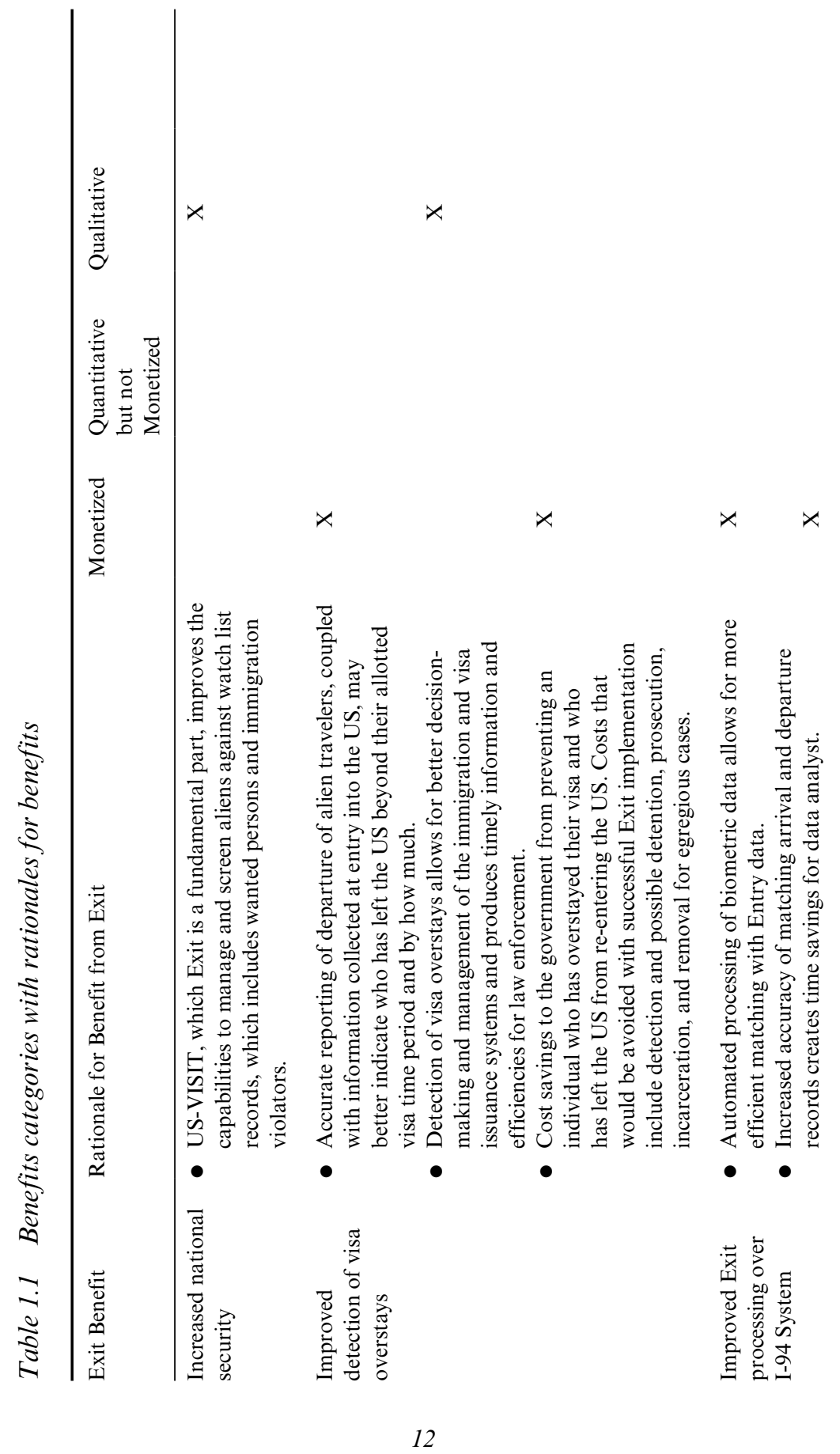





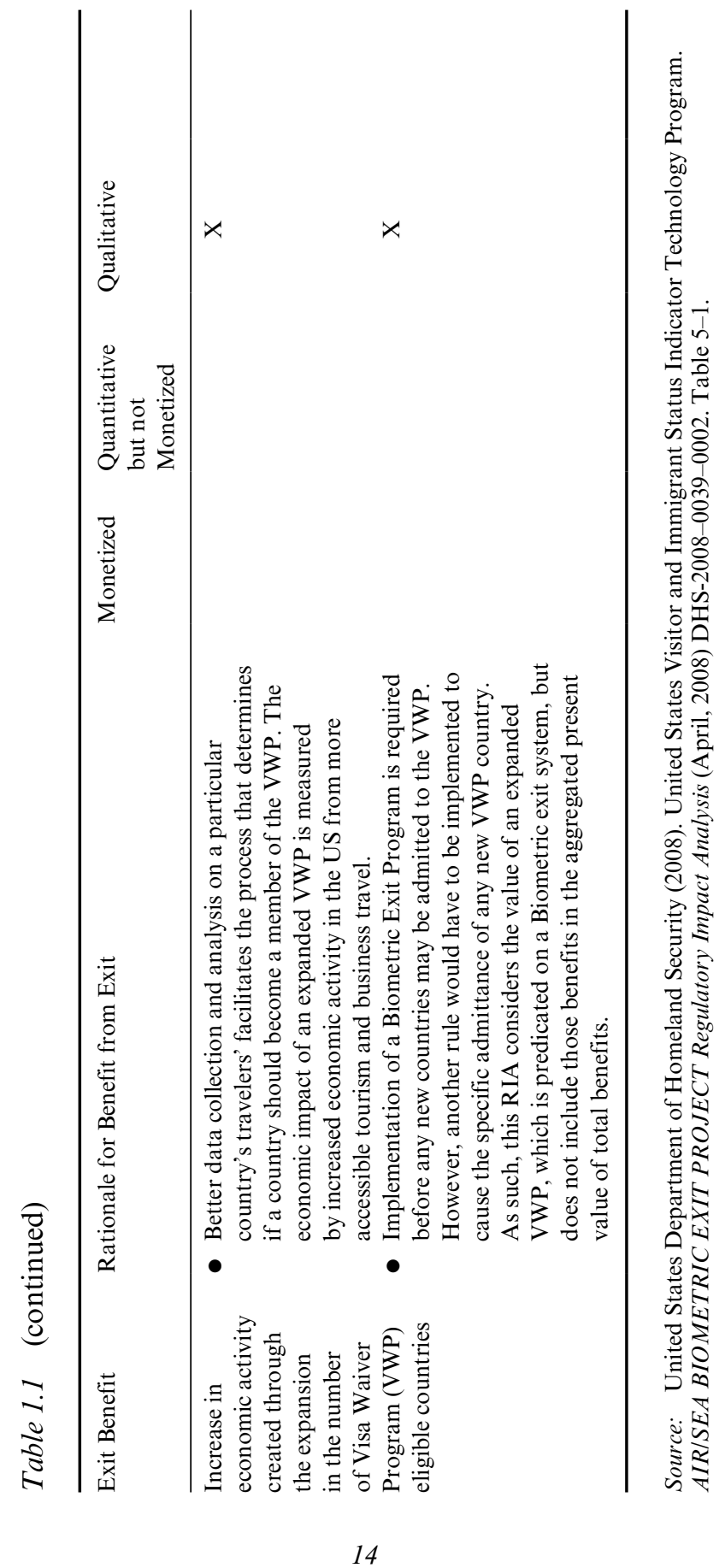




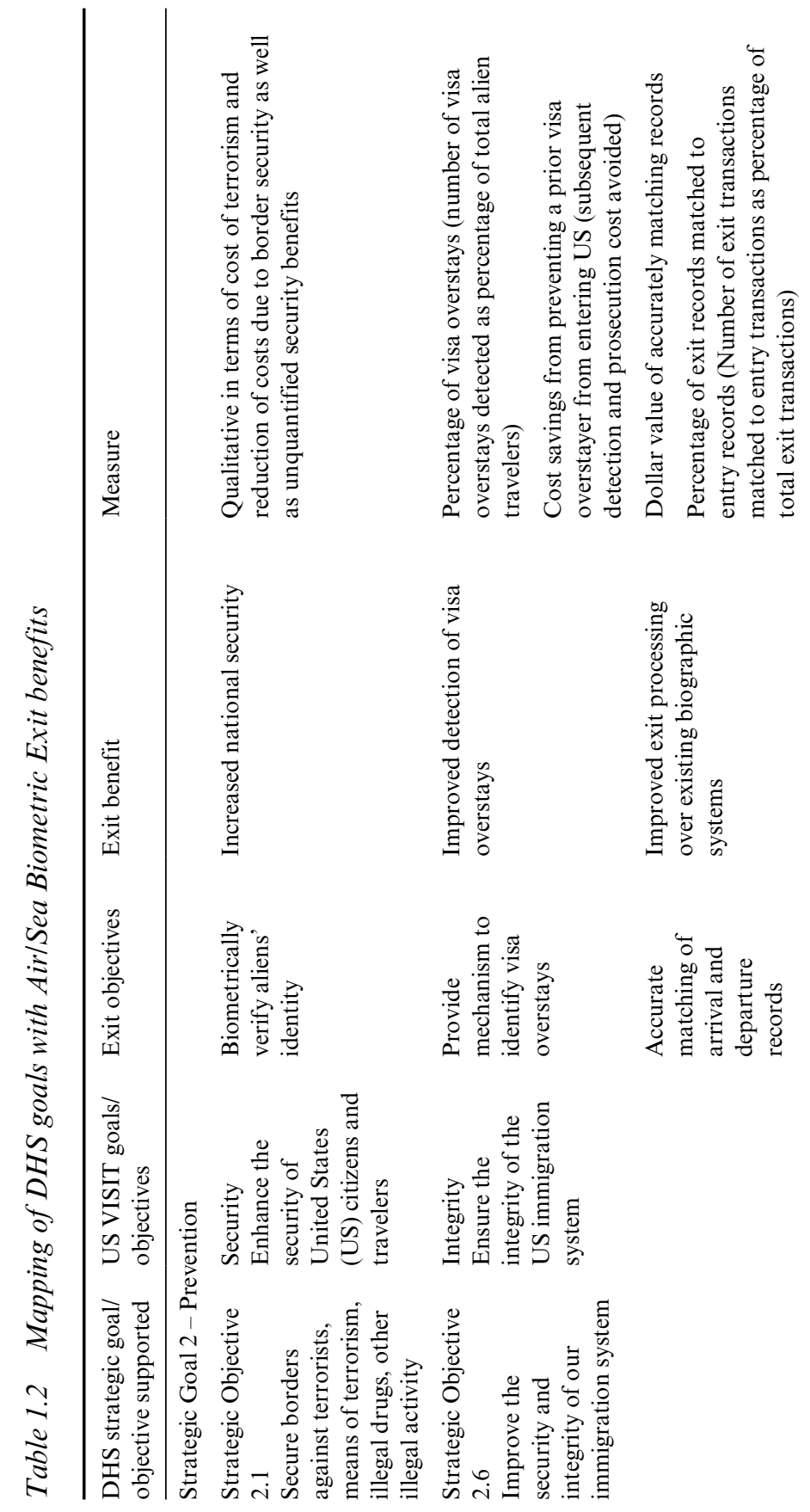




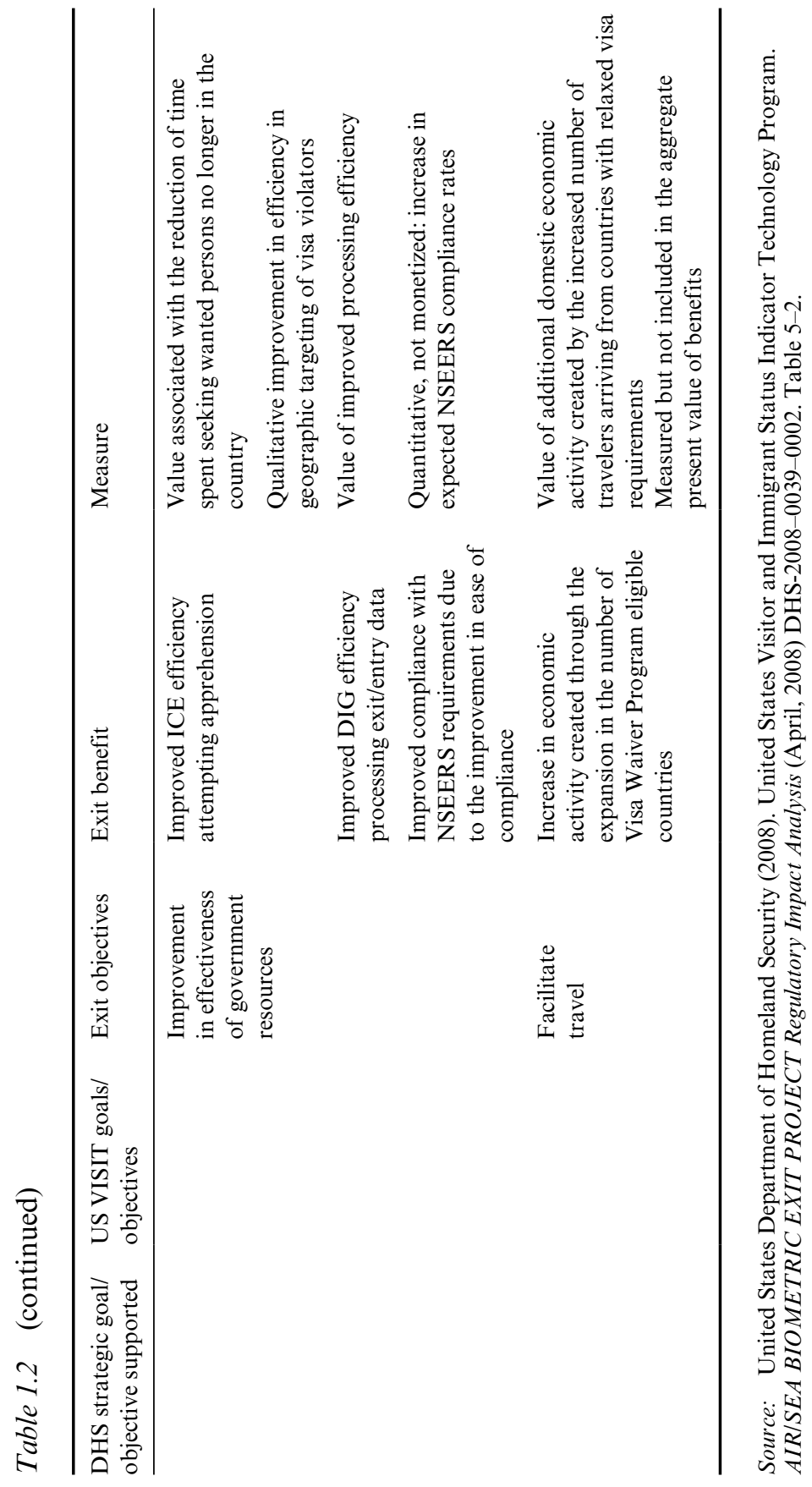


using existing data to project the future probability of attack requires an understanding of the socio-economic and political conditions motivating and facilitating attacks, and foresight about how these factors may change in the future. Faced with these limitations, the RIA did not attempt to construct quantitative estimates for either the baseline probability of terrorist attacks or the incremental reductions from this baseline.

Estimating willingness to pay (WTP) for the reduction in risk also posed challenges. The value of lost property and the opportunity costs associated with supply-chain effects can be determined from market data. However, it is difficult to estimate the WTP for a reduction in personal risks of loosely specified events that may pose threats to an individual's health. Indeed, as we noted earlier, this task may be better characterized as an effort to reduce the ambiguity in risk. That is, people may feel that without the policy they are less secure. This interpretation assumes that their anxiety arises from observing terrorist events outside the areas where they live. These events serve as reminders that 'it could happen here'. People may feel that their day-to-day activities are also insecure. There is evidence that such concerns do affect people's attitudes and behaviors. For example, Slovic's (1987) early and influential research found that the public is less willing to tolerate risks related to incidents they dread, ${ }^{9}$ such as nuclear accidents or terrorist attacks, than incidents that are not dreaded but that pose similar or higher risks, such as riding a motorcycle. The RIAs note that while some of these effects may be qualitatively described, the literature lacks quantitative estimates that account for factors like dread. The literature does contain estimates of the value of changes in fatal and nonfatal risks; however, the RIAs discuss how the value of a risk reduction may depend on risk perceptions.

These examples support our suggestion that the evaluation of security policies is especially challenging. We need to distinguish policies that reduce prospective threats from those that provide mechanisms to respond to events (whether terrorist-related or due to natural disasters) after the fact. While there are parallels at the conceptual level between the needs for these assessments and other applications of benefit-cost analysis, the information needs for security-related policy are especially pronounced.

The first step in building a framework for the economic impact analyses envisioned in the evaluation of either new rules (or for large modifications to existing regulations) requires policymakers to decide what simplifications can be tolerated for the sake of getting started. In some respects, the RIAs we selected as examples reflect an effort to jump into benefit-cost analysis without answering this question. The analysis structure for RIAs associated with the DHS rules is not necessarily a simple modification of practices used in different contexts. We argue in the next chapter that the 
process of building a framework for security policy assessment should start with a conceptual analysis of the types of outcomes influenced by policy, and their effects on people. It is possible to decide which analysis compromises can be tolerated and which cannot. Once an initial strategy for conducting analyses of DHS proposed rules is developed, it is then possible to learn from the process of doing assessments. The research presented in the chapters that follow was developed with this idea in mind. It outlines the elements that need to be addressed in order to structure an initial 'analysis platform'. In the next chapter, we use the analysis platform concept to describe the architecture of policy analysis and evaluation.

\section{WHAT IS NEXT}

The Exit RIA contains a table (reproduced in Table 1.2) that maps the DHA strategic goals to the benefits of the rules. The benefits listed in the table are high-level benefits. The next step would be to describe exactly how the rules affect specific classes of households and businesses (including the public sector), in order to make clear the pathways through which the rules will have an impact on society's welfare. Chapter 2 in this volume discusses the importance of developing such a framework to link regulations to consequences for people, firms, and other institutions. After describing some of the important steps in a benefit-cost analysis, the chapter provides a short summary of revealed and stated preference methods. We use the stated-preference surveys we conducted that were designed to map into security-related policy questions for our examples. The chapter suggests a candidate for an architecture or framework for assessing benefits and costs of homeland security policies, and describes how an existing RIA could be used to help build this type of framework. An important distinction highlighted in this chapter is the ex ante versus ex post perspective on policy evaluation. The former naturally fits policies designed to protect against security threats.

After these two introductory chapters, the volume is organized into three further parts. Part II is composed of four chapters. It considers several perspectives on security policy when such policy is characterized as an effort to reduce risk. We selected the Environmental Protection Agency (EPA) policy architecture as an example relevant to DHS, because EPA has developed protocols for a wide array of risk assessments. Chapter 3 discusses the potential parallels between EPA's generic risk-assessment methodology and DHS risk assessment. Chapter 4 provides an overview of the theoretical and empirical issues that help analysts parse the diverse estimates of the trade-offs people would make to reduce the risks 
of premature death. Chapter 5 provides a UK perspective on how these trade-off measures have been used in an array of policy contexts. Its author, Michael Jones-Lee, has been at the center of many of these assessments, and he provides both conceptual and practical insights into their role in policy analyses. Chapter 6 discusses the parallels between security risks and the risks posed by natural hazards, considering both ex ante and ex post issues.

Turning to the first contribution in Part II, Chapter 3 provides the insider's view of the risk assessment process in EPA, emphasizing the interaction between the design of risk assessment methods and the flexibility of consistently linking the outcome measures and the risks to the economic measures of the trade-offs people would make to reduce risk. EPA's process has four distinct steps:

1. hazard identification;

2. dose response assessment;

3 . exposure assessment; and

4. risk characterization.

Coordination in the definition of important health endpoints and risk measures is a key theme. An effort, such as that envisioned in developing these definitions requires collaboration and genuine interdisciplinary research. It demands an understanding of the fact that endpoints need to be defined from two potentially different perspectives that can be conflicting in their implications. First, they must allow for meaningful health science research that characterizes the role exposures to the regulated pollutants play in influencing the risks of these outcomes. At the same time, the second requirement is that the outcomes be meaningful and understandable to the people who would experience health effects and potentially be willing (ex ante) to give up resources to reduce the risks. The two perspectives do not necessarily lead to the same set of definitions.

Both the temporal dimensions of outcomes and the physical responses that result from exposure to pollutants can be different. For example, we might be able to accurately characterize how exposures to ozone over short intervals affect lung function measured in terms of forced expiratory function of lungs. What does this outcome mean to the person experiencing it? How does it relate to their longer-term health and life expectancy? The authors, Dockins and Wheeler, use thyroid condition versus thyroid cancer to make the same point. Disparities that cannot be reconciled may imply different strategies for evaluating rules such as cost effectiveness or breakeven analyses. The chapter highlights these and other alternatives. The authors implicitly suggest that it may be possible to design these 
analyses so they serve to complement benefit-cost analyses in situations were measurement is currently impossible. That is even in cases where some of the outcomes of a policy can not be defined in terms that would reconcile the outcome measures from the risk assessment perspective with the needs for examining economic trade-offs, there is value in being consistent with the overall logic of a benefit-cost analysis. The consistency in describing the process has direct value to those attempting to use quantitative and qualitative information to make decisions.

Chapter 4 by Viscusi describes the definition and properties of ex ante trade-off measures for reductions in mortality risks. Labeled as the value of statistical lives (VSL), these estimates are among the most important elements in EPA's benefit-cost analyses. Viscusi's work has been a major influence on these analyses for the past two decades. His chapter explains the reasons for heterogeneity in these estimates as a result of differences in people's circumstances: age, health conditions, income, and other factors. As he acknowledges, there are many important economic reasons why we should expect trade-offs to be different. Of course, the differences do not mean the estimates used in policy evaluations should incorporate heterogeneity. He notes that:

Policies that affect the population broadly and do not have targeted effects might well rely on overall VSL estimates without recognizing the potential variation in these values across the population ... when the VSL estimates are derived from segmented labor markets in which different labor market groups force quite different opportunities, it may be quite inappropriate to incorporate such differences in the analysis.

After a brief summary of the history of using VSL estimates for policy he comments on recent controversies such as:

- the so-called 'senior discount' associated with adjusting VSL estimates down for older groups;

- the income elasticity of the VSL and the importance of adjusting for income changes;

- the adjustment of the VSL for the size of the risk change;

- the treatment of VSL with risk having different latency and transition to death.

In each case the chapter provides a balanced summary of the context and issues in evaluating the relevance of each question for policy uses of VSL estimates.

The chapter closes with a discussion reinforcing an important motivation for the workshop and subsequent research leading to this volume. 
Most people view the risks posed by terrorism differently from the context used for most VSL estimates. There are also important differences with the risks of natural disasters. As a result, there is a clear need for research to understand how the elements of security-related threats influence the trade-offs people would make. However, this need does not imply that reductions in security-related risks are so important that they trump all other risk reduction programs.

Chapter 5 builds on Viscusi's insights using the experience with incorporating benefit measures for policy-related risk changes in the UK. JonesLee's assessment of the implications of heterogeneity parallels that of Viscusi, concluding that for policy purposes, where the events at risk and the structure creating the mortality risk are comparable, a common value for all groups affected is likely the most feasible.

He describes experience in using VSL-type measures for policy related to workplace safety, transport, railways, environmental risks, and access to natural health treatments. As a rule, policies tended to adopt a common estimate for VSLs or for the value of a statistical life year. He concludes that there has been no policy consensus on attaching a differential premium for risks of multiple fatalities over what would be implied by ruling the expected fatalities by the consensus VSL.

Of course, he notes that benefit-cost comparisons should not be the exclusive criterion for decision-making. An important example is the case of the UK's decision to offer a new health treatment to participants in the public health insurance system without cost. One strategy for evaluating which treatments qualify would be based on a comparison of the cost of the treatment per remaining life year compared to the affected population, relative to estimates of the value of a statistical life year. Those treatments with costs per remaining year of life expectancy lower than this estimated trade-off would pass one criterion. Others are also included in the discussions. Moreover, as he notes, there has been increased consideration given to multiple objective scaling techniques for these assessments.

Chapter 5 concludes with a qualified recommendation. The UK evidence on policies to reduce the risks for multiple fatality railway accidents suggest people do not assign higher trade-offs per fatality than would be implied with risks associated with single-fatality events. Based on this result, security-related risks to people's lives might be able to use VSL estimates as a starting point. In interpreting this suggestion it is important to emphasize his 'starting point' qualification.

Chapter 6 by Farrow helps readers to understand the complexities that arise in attempts to transfer risk trade-off measures from one context to another in quite different situations. He considers how the interpretation of these trade-off measures changes with three separate variations on the 
models used to represent individual behavior: state-dependent preferences, non-expected utility models, and endogenous risk. We return to these distinctions in discussing research needs in our closing chapter.

Part III of the volume considers some of the effects that security policy is likely to have. Chapter 7 discusses how much we can expect the spatial distribution of economic activity (and people) to adapt in response to security threats. Using analogies to natural disasters Kahn argues that the productivity enhancing effects of central cities more than offsets suburbanization in response to security threats that differentially affect what might be labeled 'signature cities'. More generally, his argument identifies a set of important private responses to security threats. Economic activity adjusts, reducing the harm from terrorist threats based on the 'old' organization of economic activity. As a result, policy must consider both the endogeneity of risk due to the response of the agents creating threat responses to new security policy and the private, longer term responses by societies that face persistent threats.

How do we put these considerations together? We need a structural representation of behaviors that integrate all the margins for adjustment to the sources of threats, the entities providing security, and the agents responding to external threats to their well-being and assets. No doubt this is a tall order. It implies a very different type of general equilibrium model to characterize a wider array of market and non-market interactions.

Chapter 8 by Rose describes how general equilibrium effects can matter, and how the elements in computable general equilibrium models (CGE) can be modified to incorporate resilience and to account for behavioral responses to the 'fear' associated with threats to security.

The chapter provides examples of six types of threats including quantitative assessments of the impacts for specific examples from past research. Rose extracts common elements that can be used to characterize these threats, including: the lethality of the source of risk; the concentration of people affected and their ability to mitigate the risk; the level of protection of the target of a security attack; the duration of the event associated with the risk; the fear of repeated attacks; the ability to respond in the future; and the resilience of the social and economic systems to the attack. Using the template of a CGE model, the chapter discusses the elements that must be combined to structure a CGE model. The process highlights the information that can be consistently derived from these frameworks as well as the margins where future research is needed to reflect, more completely, the diverse elements in the security-related examples he presents. The result is a window into 'generalizing general equilibrium analysis' to address security policy.

Part IV, the last part of the book, addresses some of the issues associated 
with implementing policy evaluations. Chapter 9 discusses one of the most visible effects of security policy: people must spend more of their time in security-related lines for air travel and at some entry points into the US. Waiting in lines to clear security, process baggage, or obtain new documentation to undertake various types of travel and business all increase the costs of undertaking market and non-market activities. Often these costs are not routinely recorded as a market transaction would be. They are important costs nonetheless.

As a result, we begin our discussion of implementation issues in Part IV by asking what we know about measuring the opportunity cost of time. This chapter reviews the strategies that have been used to estimate the shadow value of time, recognizing that the task is not as simple as suggesting that it should be the wage rate for people who are working. Even for those working, the shadow value will depend on commitments, the timing and amounts of time required, and ability to multi-task. Fortunately, access to new data resources, for example the American Time Use Survey, is advancing our understanding of how people and new technologies are rapidly adapting to constraints imposed by protecting security.

The second chapter in Part IV, Chapter 10 by Boyle et al., addresses the practical reality that most policy evaluations must be undertaken with whatever information is available on the research shelf. While most policy analysts have been aware of this limitation for a long time, it has been underappreciated by academic economists. There is rarely time to conduct primary research to estimate the trade-offs people would make for security-related risk reductions, time savings, or whatever is identified as an outcome of new policies. Instead, analysts must adopt estimates for comparable situations in the literature to match the needs of policy.

This approach is labeled 'benefit transfer'. Of course, it can apply equally well to cost estimation, such as the estimates used to measure the opportunity cost of time. These become especially important when we are identifying implicit costs that might be associated with increased time commitments at airports due to a new screening requirement. Often other costs of a new policy are derived from informal engineering models. To date they have received less scrutiny.

Boyle et al. provide a readers' guide to the methods used in the literature, including a careful discussion of their limitations. Given that we never know the true value of these trade-offs, even when we have time for primary research to measure them, how should we use these adapted estimates developed from these benefit transfers applied to research that was designed for another purpose? We know in advance that they are flawed. Boyle et al. remind readers of the importance of being able to bound gains 
or losses due to a decision. Not only does this narrow the range for debate and therefore limit the possibility of significant errors, it also allows simple plausibility checks. ${ }^{10}$ Every policy does not constitute a means to avoid another 9/11. Bounds also focus attention on the strategies used for implementing policies to identify ways to reduce the costs of meeting the policy's objective.

Our summary of each chapter here is deliberately brief. It is intended to pique your interest and explain why these chapters are here. We return to the themes they develop in the book's final chapter, Chapter 11, which discusses the design of a DHS platform for analysis and the new research needed to support it. An important lesson that emerges from all the chapters is that we can get started with analyses now. A council of perfection is a license to avoid hard decisions associated with the judgments that good policy analyses require. This book is intended to offer readers ideas to get started, and to advance the research that underlies these important judgments.

\section{NOTES}

1 Some authors have referred to this as another form of Frank Knight's (1921) classic discussion of risk versus uncertainty.

2. Department of Homeland Security (2011, p. 38).

3. Department of Homeland Security (2011, p. 50).

4. Department of Homeland Security (2011, p. 51).

5. We do not attempt to comment on the current status of either of these programs. Instead, we focus on the methods used to evaluate them from the perspective of the period before implementation began.

6. This is not an exact quote, but an edited paraphrasing of the statements in the RIA.

7. If the assessment of the average trade-off was per household, the approximate number to multiply would be the number of households. More generally, the issue of the 'policy extent of the market' is an important one, which we will return to in Chapter 11.

8. We return to this issue in our concluding chapter, Chapter 11, where we suggest strategies for using expert judgments that are implicit in past rules and explicit through the types of expert elicitation and risk encoding methods used by EPA and other agencies.

9. Dread associated with risk is defined as a 'perceived lack of control ... catastrophic potential, fatal consequences, and the inequitable distribution of risks and benefits' (Slovic, 1987, p. 283).

10. This strategy allows one to ask a rhetorical question as part of the policy evaluation. This question concerns how large the error in the transfer would need to be to change the decision. A variety of indirect indicators can then be used to offer information relevant to this question. In the absence of the results of the transfer it is not possible to narrow the scope for debate over the net benefits of a proposed new rule. 


\section{REFERENCES}

Burwell, S.M., C. Muñoz, J. Holdren, and A. Krueger (2013). 'Memorandum to the Heads of Departments and Agencies, subject: next steps in the evidence and innovation agenda', July 26, Executive Office of the President, Office of Management and Budget.

Hobijn, B. (2002). 'What will homeland security cost?' Federal Reserve Bank of New York Economic Policy Review, November, 21-33.

Hobijn, B. and E. Sager (2007). 'What has homeland security cost? An assessment 2002-2005', Federal Reserve Bank of New York Current Issues in Economics and Finance, 13 (February), 1-7.

Homeland Security Act (2002), 6 U.S.C. $\$ 111$ (2002).

Industrial Economics, Inc. (2008). 'Regulatory assessment for the final rule documents required for travel within the Western Hemisphere: the Western Hemisphere Travel Initiative implemented in the land environment', prepared for US Customs and Border Protection, United States Department of Homeland Security, March.

Knight, F.H. (1921). Risk, Uncertainty and Profit, New York: Harper \& Row.

Navarro, P. and A. Spencer (2001). 'September 11, 2001: assessing the costs of terrorism', Milken Institute Review, Fourth Quarter, 16-31.

United States Office of Management and Budget (OMB) (2010). Report to Congress on the Benefits and Costs of Federal Regulations and Unfunded Mandates on State, Local and Tribal Entities, Office of the President of the United States of America.

Samuelson, P.A. (1976). Economics, 10th edn, New York: McGraw Hill.

Slovic, P. (1987). 'Perception of risk', Science, 236 (April 17), 280-285.

United States Department of Homeland Security (DHS) (2008). 'Air/Sea Biometric Exit Project regulatory impact analysis DHS-2008-0039-0002', United States Visitor and Immigrant Status Indicator Technology Program, April.

United States Department of Homeland Security (DHS) (2011). Final Plan for the Retrospective Review of Existing Regulations, August 22.

United States Visitor and Immigrant Status Indicator Technology Program (2008). 'Air/Sea Biometric Exit Project regulatory impact analysis DHS-20080039-0002', April 17. 